Check for updates

Cite this: RSC Adv., 2021, 11, 39343

\title{
Eutectic-based liposome as a potential delivery system of paeonol
}

\begin{abstract}
Jieyu Wu, (D) $\dagger^{a}$ Suqin Yang, $\dagger^{b}$ Tianxiang Yin (D) *a and Xiaoyong Wang (D) ${ }^{a}$
Deep eutectic solvents (DESs), as a new type of green solvent, show great advantages of easy preparation and no need of purification after synthesis and have great potential applications in various fields. Moreover, when combining active pharmaceutical ingredients (APIs) with DESs, a new type of drug delivery system called a therapeutic deep eutectic solvent (THEDES) can be developed to increase the solubility of the APIs and/or their permeation ability as well as bioactivity. Herein, we have designed a new THEDES based on paeonol and lauric acid with a molar ratio of $1: 1$. The physicochemical properties as well as the bioactivity were investigated by a series of techniques. The THEDES showed better solubility in water and similar bioactivities as compared to the pure APIs. Besides, we further prepared a THEDES liposome, which possessed an average size of about $120 \mathrm{~nm}$ with an encapsulation efficiency of $84 \%$. The obtained liposome showed good stability during the experimental period, which indicated a potential application for the delivery of paeonol. The results presented herein suggested that THEDES may be regarded as a new strategy for the effective delivery of APIs.
\end{abstract}

Received 15th September 2021 Accepted 26th November 2021

DOI: $10.1039 / \mathrm{d} 1 \mathrm{ra06907a}$

rsc.li/rsc-advances
However, wide applications of paeonol are hindered by its poor solubility, i.e. $0.54 \mathrm{mg} \mathrm{ml}^{-1}{ }^{26}$ and low oral bioavailability. Smart formulations and/or transdermal delivery with the help of penetration enhancers may be used to effectively deliver paeonol. Herein, we developed a novel eutectic system based on paeonol and lauric acid, and investigated the corresponding physicochemical properties and bioactivities. Liposomes have been extensively investigated as effective drug delivery systems due to their easily tunable physicochemical properties and good biocompatibility. ${ }^{27-29}$ Herein, a liposome based on the paeonol-lauric acid eutectic system was constructed to evaluate its potential application in paeonol delivery.

\section{Experimental}

\subsection{Chemicals}

Paeonol ( $\geq 98 \%$ ), tyrosinase $\left(\geq 500 \mathrm{U} \mathrm{mg}^{-1}\right)$, penicillin-streptomycin solution $(100 \mathrm{X})$, L-glutamine $(\geq 99 \%)$, and cholesterol $(\geq 99.5 \%)$ were purchased from Macklin. Lauric acid ( $\geq 99 \%)$<smiles>COc1ccc(C(C)=O)c(O)c1</smiles>

Scheme 1 Chemical structure of paeonol.
${ }^{a}$ School of Chemistry and Molecular Engineering, East China University of Science and Technology, Shanghai 200237, China. E-mail: yintx@ecust.edu.cn; Fax: +86 21 64250804; Tel: +862164252012

${ }^{b}$ The Affiliated Huai'an Hospital of Xuzhou Medical University, The Second People's Hospital of Huai'an, No. 62, Huaihai Rd., Huai'an 223002, China

$\dagger$ These two authors contributed equally to this work. 
Table 1 Compositions of reaction solutions in the tyrosinase inhibitory assay

\begin{tabular}{llllll}
\hline & \multicolumn{4}{l}{ Volume $(\mathrm{ml})$} & \\
\cline { 2 - 6 } No. & PBS & DMSO & Drug $^{a}$ & L-DOPA & Tyrosinase \\
\hline 1 & 1.6 & 0.2 & 0 & 1 & 0.2 \\
2 & 1.8 & 0.2 & 0 & 1 & 0 \\
3 & 1.6 & 0 & 0.2 & 1 & 0.2 \\
4 & 1.8 & 0 & 0.2 & 1 & 0
\end{tabular}

${ }^{a}$ Both pure ingredients (paeonol and lauric acid) and THEDES were dissolved in DMSO.

Table 2 Orthogonal experiment factors and levels of preparation of the liposomes

\begin{tabular}{lllll}
\hline & Factors & & \\
\cline { 2 - 5 } Level & $\begin{array}{l}A \\
\left(\mathrm{mg} \mathrm{ml}^{-1}\right)\end{array}$ & $\begin{array}{l}B \\
(\mathrm{w} / \mathrm{w})\end{array}$ & $C(\mathrm{w} / \mathrm{w})$ & $D\left({ }^{\circ} \mathrm{C}\right)$ \\
\hline 1 & 5 & $10: 1$ & $1: 10$ & 40 \\
2 & 8 & $8: 1$ & $1: 8$ & 50 \\
3 & 10 & $5: 1$ & $1: 5$ & 60
\end{tabular}

was supplied by Alfa Aesar. Phosphate buffered saline (PBS, $\mathrm{pH}=6.8,0.01 \mathrm{M})$ was purchased from Biorigin. L-Dopa $(\geq 98 \%)$ was supplied by Duly Biotech. Co. Ltd (Nanjing, China). Lecithin (from soybean, $>90 \%$ ) was purchased from Aladdin. DMSO (Greagent, $\geq 99 \%$ ) and dichloromethane (Greagent, 99.5\%) were from Tansoole (Titan Co. Shanghai, China). CCK-8 was from Invigentech. RPMI 1640 cell culture medium and fetal bovine serum (FBS) were supplied by Biological Industries.

\subsection{Preparation and characterization of THEDES}

2.2.1 Construction of the paeonol-lauric acid eutectic solvent. Mixtures of paeonol and lauric acid at different mole fractions were prepared and heated up to $50{ }^{\circ} \mathrm{C}$. Thereafter, the samples were cooled slowly to $37^{\circ} \mathrm{C}$ with the temperature being controlled by a water bath. The sample that still remained in the liquid state was chosen as the eutectic system (denoted as THEDES) for the following investigations.

Differential scanning calorimetry experiments were carried out for paeonol, lauric acid and THEDES (mole ratio of paeonol and lauric acid being $1: 1$ ). The thermograms were recorded from $0{ }^{\circ} \mathrm{C}$ to $80{ }^{\circ} \mathrm{C}$ with a scanning rate of $5{ }^{\circ} \mathrm{C} \mathrm{min}{ }^{-1}$.

\subsubsection{Characterization of THEDES}

2.2.2.1 ${ }^{1} H$ NMR. A suitable amount of THEDES was dissolved in $\mathrm{CDCl}_{3}$, and the ${ }^{1} \mathrm{H}$ NMR spectrum was recorded by a Bruker Avance 400 spectrometer.

2.2.2.2 Viscosity and solubility measurement of THEDES. The viscosity of THEDES at $37{ }^{\circ} \mathrm{C}$ was determined by an autoviscosimeter (NDJ-5S, Hengping Co. Shanghai, China).

2.2.2.3 Solubility. The method used to determine THEDES solubility was as follows: slightly excess amount of THEDES was added to $10 \mathrm{ml}$ water. The mixture was then vigorously stirred at $37{ }^{\circ} \mathrm{C}$ for $48 \mathrm{~h}$, and was further centrifuged at $8000 \mathrm{rpm}$ for $45 \mathrm{~min}$. Thereafter, the supernate was carefully sucked and analyzed by a UV-vis spectrometer with the help of a calibration curve. The calibration curves of paeonol and THEDES were determined in aqueous solution by the UV-vis spectrometer (UV-2450, Shimadzu), which were $A=0.0848 C /$ $\left(\mathrm{mg} \mathrm{m}{ }^{-1}\right)$ for paeonol and $A=0.0399 C /\left(\mathrm{mg} \mathrm{ml} \mathrm{ml}^{-1}\right)$ for THEDES, where $A$ and $C$ refer to the absorbance and concentration, respectively. The process was repeated thrice and the average value was recorded.

2.2.3 Tyrosinase inhibitory assay. L-DOPA was used as a substrate and the absorption intensity change of its oxidation product at $475 \mathrm{~nm}$ was monitored to determine the tyrosinase inhibition efficiency. The reaction was carried out in a PBS solution containing $0.5 \mathrm{mM} \mathrm{L-DOPA}$ and tyrosinase solution $\left(500 \mathrm{U} \mathrm{ml}^{-1}\right)$ at $37^{\circ} \mathrm{C}$. The substances were added in the order shown in Table 1 (from left to right). The mixture was incubated for $15 \mathrm{~min}$ before the addition of tyrosinase.

The change of the absorbance $A$ of DOPA chrome was measured at $475 \mathrm{~nm}$ using the UV-vis spectrometer. The tyrosinase inhibitory activity was then calculated by:

$$
\text { Inhibitory Activity } \%=\frac{\left[\left(A_{1}-A_{2}\right)-\left(A_{3}-A_{4}\right)\right]}{\left(A_{1}-A_{2}\right)} \times 100 \%
$$
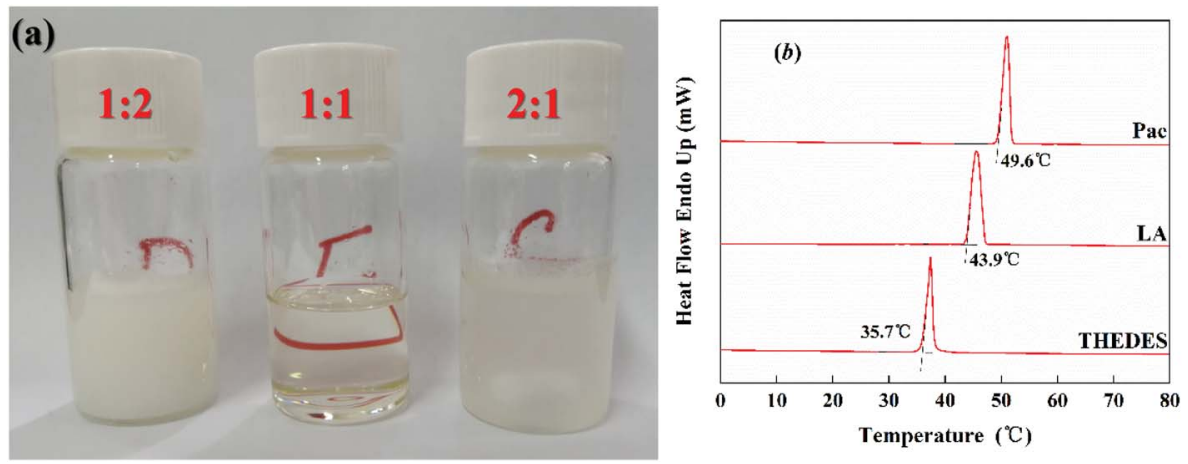

Fig. 1 (a) Images of the paeonol and lauric acid mixtures at different mole ratios (paeonol: lauric acid); (b) thermograms for the pure components paeonol (pae) and lauric acid (LA), and THEDES. 


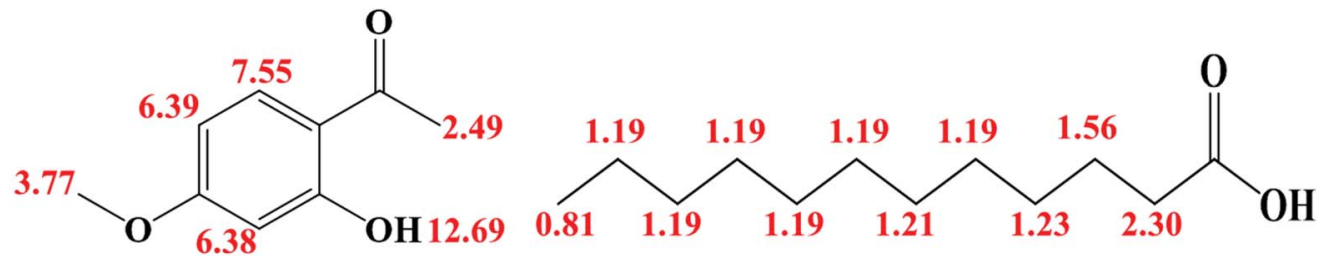

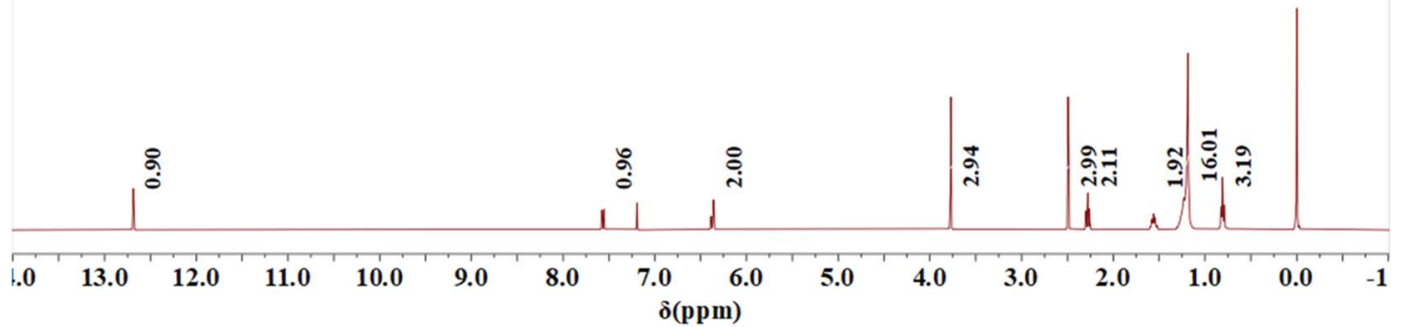

Fig. $2{ }^{1} \mathrm{H}$ NMR spectrum of THEDES.

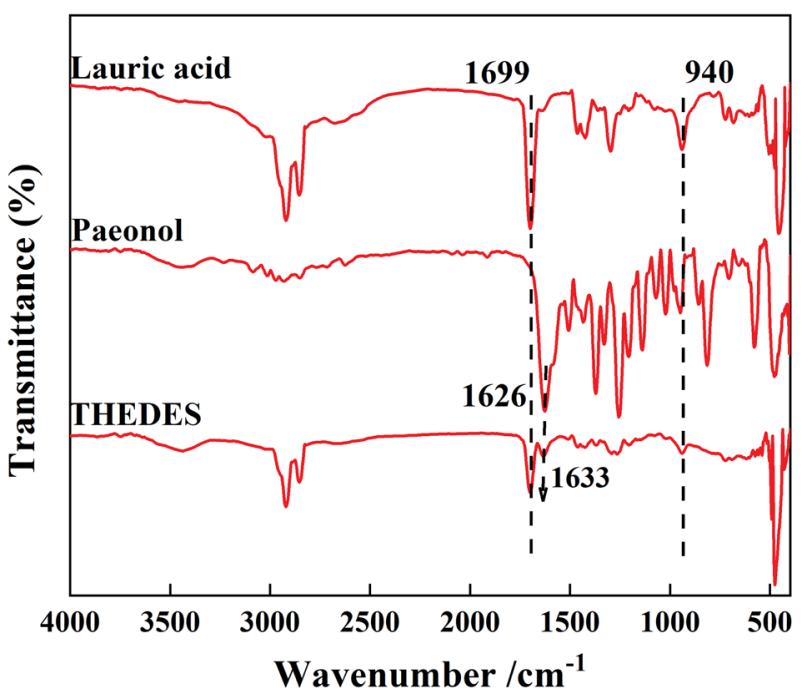

Fig. 3 FT-IR spectra of lauric acid, paeonol and THEDES.

The tyrosinase inhibitory assay was performed thrice and the average values were reported.

2.2.4 Cytotoxicity. The CCK-8 assay was used to evaluate cell viability to indicate the safety of THEDES. The L02 cell was cultured in RPMI 1640 supplemented with 10\% FBS, $200 \mathrm{U}$ $\mathrm{ml}^{-1}$ penicillin, $100 \mu \mathrm{g} \mathrm{ml^{-1 }}$ streptomycin and $0.3 \mathrm{~g} \mathrm{ml}^{-1} \mathrm{~L}^{-}$ glutamine under a humidified atmosphere of $95 \% \mathrm{CO}_{2}$ at $37^{\circ} \mathrm{C}$. The cells were seeded at a density of approximately $10^{4}$ cells per $\mathrm{ml}$ in a 96-well plate for $48 \mathrm{~h}$. Thereafter, they were incubated with THEDES, paeonol, or lauric acid at a series of concentrations. The cytotoxicity was tested by the CCK-8 method, where the optical density was measured at $450 \mathrm{~nm}$ using an automatic microplate reader (SPARK 10M, TECAN). The cell viability was displayed as a percentage compared to the untreated cells. Three independent experiments were carried out, and the average values were taken and reported with standard deviation.

\subsection{Preparation and characterization of the liposome}

2.3.1 Preparation of the liposome. The liposome was prepared by a traditional thin film hydration method. Briefly, lecithin, cholesterol, and THEDES were dissolved in $20 \mathrm{ml}$ dichloromethane with the help of ultrasound. Thereafter, the organic solvent was removed using a vacuum rotary evaporator. The thin lipid film formed on the wall of the flask was further hydrated with double distilled water for $1 \mathrm{~h}$, and the mixture was further ultra-sounded for $5 \mathrm{~min}$ to give the liposome solution.

2.3.2 Determination of encapsulation efficiency (EE). The ultrafiltration centrifugation method was used to determine the encapsulation efficiency. Ethanol was added to a certain amount of liposome solution to break down the liposomes. The absorbance of the obtained solution at $274 \mathrm{~nm}$ was determined by a UV-vis spectrometer and denoted as $A_{0}$. On the other hand, $0.4 \mathrm{ml}$ liposome solution was added to an ultrafiltration centrifuge tube with a molecular weight cutoff of $10 \mathrm{KDa}$, which was centrifuged at a working speed of $8000 \mathrm{rpm}$ for $40 \mathrm{~min}$. The lower part of the solution was carefully taken, whose absorbance at $274 \mathrm{~nm}$ was measured by a UV-vis spectrometer and denoted as $A_{1}$. Thus, the encapsulation efficiency was calculated by:

$$
\mathrm{EE}=\frac{A_{0}-A_{1}}{A_{0}} \times 100 \%
$$

2.3.3 Optimization of the formula of the liposome. Four main factors that have shown significant impacts on the encapsulation efficiency, i.e. lecithin concentration $(A)$, lecithinto-cholesterol ratio $(B)$, drug-to-lecithin ratio $(C)$ and hydration temperature $(D)$, were chosen to design a four-factor three-level orthogonal test with encapsulation efficiency as the evaluation index. The orthogonal test factors and levels of the preparation process of the liposomes are shown in Table 2 .

2.3.4 Characterization of the liposome. The size distribution and zeta potential of the liposome were determined using a Malvern Zetasizer Nano ZS instrument (Southborough, MA) 
(a)

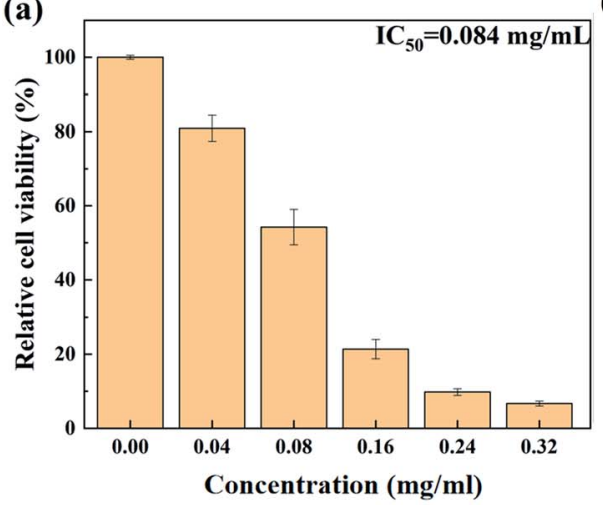

(b)

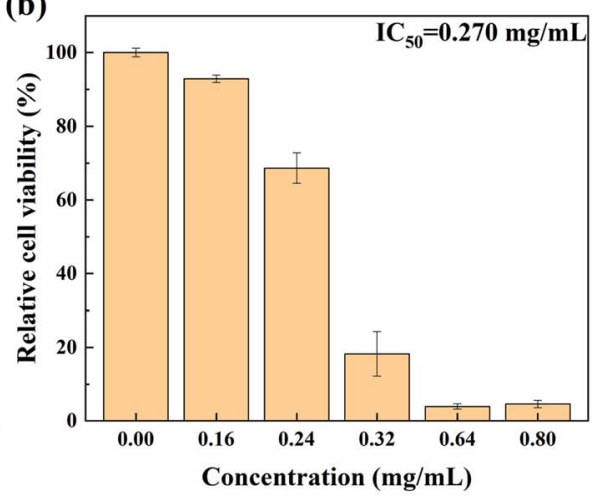

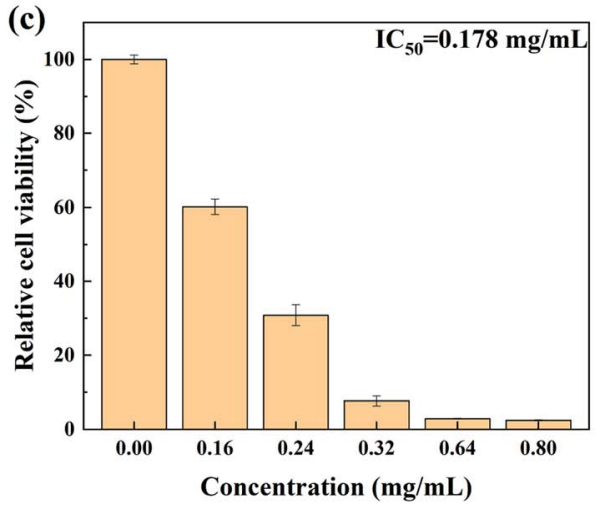

Fig. 4 Cytotoxicity of THEDES (a), paeonol (b) and lauric acid (c) using L02 cells.

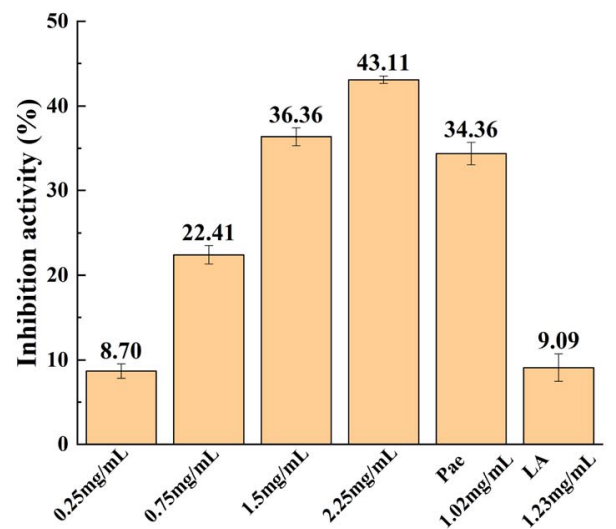

Fig. 5 Inhibition activities of THEDES at various concentrations and those of the pure components lauric acid (LA) and paeonol (pae).

with a backscattering detector $\left(173.8^{\circ}\right)$ and a laser with $633 \mathrm{~nm}$ wavelength. Measurements were taken in batch mode at 298.15 $\mathrm{K}$ using a plastic cuvette with a path length of $1 \mathrm{~cm}$.

Negative stained transmission electron microscopy (NSTEM) measurements were performed to show the morphology of the liposome. A drop of liposome solution was placed on a carbon-coated copper grid (300 meshes), and the excess was removed by filter paper. After that, a drop of $1 \%$ phosphotungstic acid solution was dropped on the copper grid as the staining agent, and the excess liquid was removed after $15 \mathrm{~s}$. The image of the sample after drying at room temperature was obtained using a JEM-1400 electron microscope at a working voltage of $80 \mathrm{kV}$.

\section{Results and discussions}

\subsection{Preparation and physicochemical properties of THEDES}

The images of paeonol and lauric acid at different mole ratios were obtained at $37^{\circ} \mathrm{C}$ and some of these samples are displayed in Fig. 1a. The eutectic system occurs when the mole ratio of paeonol and lauric acid is $1: 1$. Furthermore, the thermograms of the pure components and THEDES were collected and are displayed in Fig. 1b. The melting temperatures for paeonol and lauric acid as well as the eutectic temperature were determined to be $49.6{ }^{\circ} \mathrm{C}, 43.9^{\circ} \mathrm{C}$, and $35.7^{\circ} \mathrm{C}$, respectively.

THEDES was verified by a ${ }^{1} \mathrm{H}$ NMR experiment, as displayed in Fig. 2. It can be estimated from Fig. 2 that the ratio of the peak area between $\delta=12.69(-\mathrm{OH}$ in paeonol) and $\delta=0.8(\mathrm{~m}$, $-\mathrm{CH}_{3}$ in Lauric acid) is about 3; that is, the mole ratio of paeonol to lauric acid is nearly $1: 1$ in THEDES. The interaction between the $-\mathrm{COOH}$ group in lauric acid and the $\mathrm{OH}$ group in paeonol can be speculated from the FT-IR spectra, shown in Fig. 3, where the $\mathrm{C}=\mathrm{O}$ stretching peak at $1626 \mathrm{~cm}^{-1}$ of paeonol moves towards a higher wavenumber from $1626 \mathrm{~cm}^{-1}$ to $1633 \mathrm{~cm}^{-1}$. Moreover, the ratio of the absorbance between the $-\mathrm{OH}$ bending peak at $940 \mathrm{~cm}^{-1}$ of lauric acid and the $\mathrm{C}=\mathrm{O}$ stretching peak at 
Table 3 Results of the orthogonal test

\begin{tabular}{lccccc}
\hline & Factors & & & & \\
\cline { 2 - 5 } No. & $A$ & $B$ & $C$ & $D$ & EE (\%) \\
\hline 1 & 1 & 1 & 1 & 1 & 75.8 \\
2 & 1 & 2 & 2 & 2 & 78.1 \\
3 & 1 & 3 & 3 & 3 & 72.3 \\
4 & 2 & 1 & 2 & 3 & 75.1 \\
5 & 2 & 2 & 3 & 1 & 74.1 \\
6 & 2 & 3 & 1 & 2 & 76.4 \\
7 & 3 & 1 & 3 & 2 & 80.8 \\
8 & 3 & 2 & 1 & 3 & 81.3 \\
9 & 3 & 3 & 2 & 1 & 76.1 \\
$K_{1}$ & 75.4 & 77.2 & 77.8 & 75.3 & \\
$K_{2}$ & 75.2 & 77.8 & 76.5 & 78.4 & \\
$K_{3}$ & 79.4 & 74.9 & 75.7 & 76.2 & \\
$R$ & 4.21 & 2.90 & 2.10 & 3.11 & \\
& & & & &
\end{tabular}

$1699 \mathrm{~cm}^{-1}$ of lauric acid declined obviously, which further indicated the interaction between lauric acid and paeonol.

The solubility of THEDES in water was measured to be $1.67 \pm$ $0.02 \mathrm{mg} \mathrm{ml}^{-1}$ (the corresponding amount of paeonol is $0.76 \mathrm{mg}$ $\mathrm{ml}^{-1}$ ). The solubility of paeonol in water was also measured herein to be $0.59 \mathrm{mg} \mathrm{ml}^{-1}$, which was similar to the reported value $\left(0.54 \mathrm{mg} \mathrm{ml}{ }^{-1}\right) \cdot{ }^{26} \mathrm{Up}$ to $30 \%$ increase in solubility for paeonol was achieved by the formation of THEDES, which was better than the previously reported eutectic system formed by paeonol and menthol (molar ratio of $4: 6$ ). ${ }^{30}$ The viscosity of THEDES at a temperature of $37{ }^{\circ} \mathrm{C}$ was determined to be 6.31 $\mathrm{mPa} \cdot \mathrm{s}$, which displayed a relatively low viscosity as compared to other commonly investigated DES systems.

To evaluate the safety of THEDES for its application, the cytotoxicity of THEDES was determined and compared to those of paeonol and lauric acid, which are displayed in Fig. 4. The $\mathrm{IC}_{50}$ values for paeonol, lauric acid, and THEDES were calculated to be $0.084 \mathrm{mg} \mathrm{ml}^{-1}, 0.270 \mathrm{mg} \mathrm{ml}^{-1}$, and $0.178 \mathrm{mg} \mathrm{ml}^{-1}$, respectively. For THEDES, the molar ratio of paeonol to lauric acid is $1: 1$, which gives a mass ratio of $1: 1.2$. For $0.178 \mathrm{mg}$ $\mathrm{ml}^{-1}$ THEDES $\left(\mathrm{IC}_{50}\right)$, the corresponding concentrations of paeonol and lauric acid were $0.08 \mathrm{mg} \mathrm{ml}^{-1}$ and $0.098 \mathrm{mg} \mathrm{ml}^{-1}$, respectively. As compared to the relative cell viability at these concentrations for pure paeonol and lauric acid, it can be found that THEDES presented slightly lower cytotoxicity.

Moreover, in order to show the bioactivity of THEDES, the inhibitory activity on tyrosinase of THEDES was evaluated and compared to those of the pure components (paeonol and lauric acid). The results of the inhibitory activity tests are shown in Fig. 5, which shows that the tyrosinase inhibitory activity of THEDES increases with concentration. Moreover, the inhibition activity of THEDES with a concentration of $2.25 \mathrm{mg} \mathrm{ml}^{-1}$ is similar to the sum of those of paeonol and lauric acid at the same concentrations as those in THEDES, which indicates that THEDES retains the bioactivity of the pure APIs.

\subsection{THEDES-based liposome}

The preparation process of the THEDES-based liposome was optimized by a $\mathrm{L}_{9}(34)$ orthogonal test. The results are displayed in Table 3.

From Table 3, it can be speculated that the order of the factors affecting the encapsulation efficiency of the THEDES liposome is as follows: lecithin concentration $(A)>$ hydration temperature $(D)>$ lecithin-to-cholesterol ratio $(B)>$ drug-tolecithin ratio $(C)$. The optimized parameters for the preparation of the THEDES liposome were determined to be: lecithin concentration $\left(10 \mathrm{mg} \mathrm{ml}^{-1}\right)$, hydration temperature $\left(50{ }^{\circ} \mathrm{C}\right)$, lecithin-to-cholesterol ratio $(8: 1)$, and drug-to-lecithin ratio $(1: 10)$. Under this condition, three different batches of liposome were prepared and the encapsulation efficiencies were measured to be $84.5 \%, 83.9 \%$, and $84.1 \%$, which showed good reproducibility. The liposome obtained in the optimized condition was thus used in the following studies.

The size distribution and morphology of the obtained liposome were determined by the methods of dynamic light scattering and TEM, respectively, which are displayed in Fig. 6a and b, respectively. An average size of $117.5 \pm 0.6 \mathrm{~nm}$ with PDI $=$ 0.283 was obtained by the dynamic light scattering measurement (Fig. 6a), which shows reasonable agreement with that observed by TEM (Fig. 6b).

The zeta potential was determined to be $-16.1 \pm 0.2 \mathrm{mV}$, which may result in good stability of the prepared liposome. This was further checked by a stability test, where the prepared liposome solution was stored at $4{ }^{\circ} \mathrm{C}$ for three months. The size
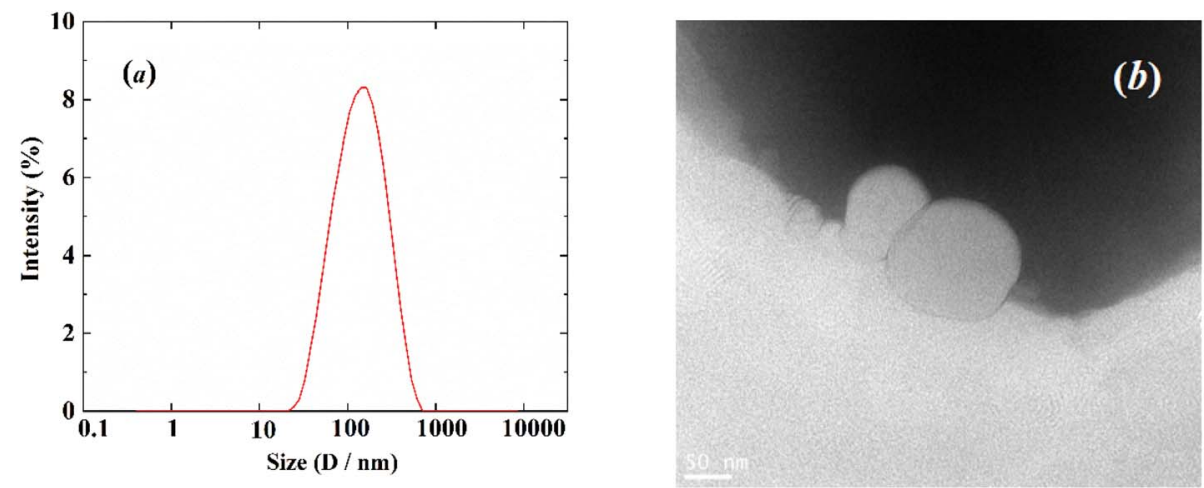

Fig. 6 (a) Size distribution of the liposome from dynamic light scattering measurement; (b) TEM image of the liposome. 
of the liposome, zeta potential, and encapsulation efficiency (EE) were re-determined to be $124.2 \pm 0.5 \mathrm{~nm},-14.7 \pm 0.3 \mathrm{mV}$ and $81.7 \%$, respectively; no obvious changes of these properties can be observed. These results indicated the good stability of the liposome and the great potential of this THEDES-based liposome as an efficient drug delivery system for paeonol.

\section{Conclusion}

In this work, we have designed a new THEDES based on paeonol and lauric acid with a molar ratio of $1: 1$. The physicochemical properties as well as the bioactivity were investigated by various methods. THEDES showed better solubility in water and similar inhibitory activity on tyrosinase as compared to the pure APIs. Moreover, THEDES displayed slightly weaker cytotoxicity than the pure components. We further prepared the THEDES liposome under optimized conditions of lecithin concentration (10 $\left.\mathrm{mg} \mathrm{ml} \mathrm{m}^{-1}\right)$, hydration temperature $\left(50{ }^{\circ} \mathrm{C}\right)$, lecithin-tocholesterol ratio $(8: 1)$, and drug-to-lecithin ratio $(1: 10)$. The obtained liposome possessed an average size of about $120 \mathrm{~nm}$ and an encapsulation efficiency of $84 \%$. The liposome showed good stability during the experimental period of about 3 months. These results presented herein indicate the great potential of this THEDES-based liposome as an efficient drug delivery system for paeonol.

\section{Conflicts of interest}

There are no conflicts to declare.

\section{Acknowledgements}

This work was supported by the National Natural Science Foundation of China (Projects 21773063).

\section{References}

1 A. P. Abbott, G. Capper, D. L. Davies, R. K. Rasheed and V. Tambyrajah, Chem. Commun., 2003, 70-71.

2 A. P. Abbott, D. Boothby, G. Capper, D. L. Davies and R. K. Rasheed, J. Am. Chem. Soc., 2004, 126, 9142-9147.

3 D. V. Wagle, H. Zhao and G. A. Baker, Acc. Chem. Res., 2014, 47, 2299-2308.

4 F. Pena-Pereira and J. Namiesnik, ChemSusChem, 2014, 7, 1784-1800.

5 D. A. Alonso, A. Baeza, R. Chinchilla, G. Guillena, I. M. Pastor and D. J. Ramón, Eur. J. Org. Chem., 2016, 2016, 612-632.

6 P. Xu, G. W. Zheng, M. H. Zong, N. Li and W. Y. Lou, Bioresour. Bioprocess., 2017, 4, 34.

7 S. Sarmad, J. P. Mikkola and X. Y. Ji, ChemSusChem, 2017, 10, 324-352.

8 D. J. Tao, F. Qu, Z. M. Li and Y. Zhou, AIChE J., 2021, 67, e17106.

9 D. Cao, Q. Liu, W. Q. Jing, H. Y. Tian, H. Y. Yan, W. T. Bi, Y. L. Jiang and D. D. Y. Chen, ACS Sustainable Chem. Eng., 2020, 8, 19169-19177.
10 B. B. Hansen, S. Spittle, B. Chen, D. Poe, Y. Zhang, J. M. Klein, A. Horton, L. Adhikari, T. Zelovich, B. W. Doherty, B. Gurkan, E. J. Maginn, A. Ragauskas, M. Dadmun, T. A. Zawodzinski, G. A. Baker, M. E. Tuckerman, R. F. Savinell and J. R. Sangoro, Chem. Rev., 2021, 121, 1232-1285.

11 D. K. Yu, Z. M. Xue and T. C. Mu, Chem. Soc. Rev., 2021, 50, 8596-8638.

12 I. M. Aroso, J. C. Silva, F. Mano, A. S. D. Ferreira, M. Dionisio, I. Sa-Nogueira, S. Barreiros, R. L. Reis, A. Paiva and A. R. C. Duarte, Eur. J. Pharm. Biopharm., 2016, 98, 57-66.

13 A. P. Abbott, E. I. Ahmed, K. Prasad, I. B. Qader and K. S. Ryder, Fluid Phase Equilib., 2017, 448, 2-8.

14 A. R. C. Duarte, A. S. D. Ferreira, S. Barreiros, E. Cabrita and R. L. Reis, Eur. J. Pharm. Biopharm., 2017, 114, 296-304.

15 A. Gutiérrez, S. Aparicio and M. Atilhan, Phys. Chem. Chem. Phys., 2019, 21, 10621-10634.

16 J. M. Silva, C. V. Pereira, F. Mano, E. Silva, V. I. B Castro, I. SáNogueira, R. L. Reis, A. Paiva, A. A. Matias and A. R. C. Duarte, ACS Appl. Bio. Mater., 2019, 2, 4346-4355.

17 S. N. Pedro, M. G. Freire, C. S. R. Freire and A. J. D. Silvestre, Expert Opin. Drug Delivery, 2019, 16, 497-506.

18 P. Angsantikul, K. Peng, A. M. Curreri, Y. Chua, K. Z. Chen, J. Ehondor and S. Mitragotri, Adv. Funct. Mater., 2021, 31, 2002912.

19 Md S. Rahman, R. Roy, B. Jadhav, Md N. Hossain, M. A. Halim and D. E. Raynie, J. Mol. Liq., 2021, 321, 114745.

20 T. R. Sekharan, O. Katari, S. N. R. Rahman, D. M. Pawde, A. Goswami, R. M. Chandira and T. Shunmugaperumal, Drug Discovery Today, 2021, 26, 1702-1711.

21 S. Li, A. Culkin, D. S. Jones and G. P. Andrews, Int. J. Pharm., 2021, 593, 120071.

22 F. Al-Akayleh, S. Adwan, M. Khanfar, N. Idkaidek and M. AlRemawi, AAPS PharmSciTech, 2021, 22, 4.

23 L. Zhang, D. C. Li and L. F. Liu, Int. Immunopharmacol., 2019, 72, 413-421.

24 K. M. Adki and Y. A. Kulkarni, Life Sci., 2020, 250, 117544.

25 H. Y. Li, J. Zhu, C. F. Wang, W. Qin, X. X. Hu, J. B. Tong, L. Yu, G. Q. Zhang, X. H. Ren, Z. G. Li and J. W. Zhang, Int. J. Pharm., 2020, 587, 119649.

26 H. Y. Li, J. Zhu, C. F. Wang, W. Qin, X. X. Hu, J. B. Tong, L. Yu, G. Q. Zhang, X. H. Ren, Z. G. Li and J. W. Zhang, Int. J. Pharm., 2020, 587, 119649.

27 D. Guimarães, A. Cavaco-Paulo and E. Nogueira, Int. J. Pharm., 2021, 601, 120571.

28 D. E. Large, R. G. Abdelmessih, E. A. Fink and D. T. Auguste, Adv. Drug Delivery Rev., 2021, 176, 113851.

29 N. Filipczak, J. Pan, S. S. K. Yalamarty and V. P. Torchilin, Adv. Drug Delivery Rev., 2020, 156, 4-22.

30 W. P. Wang, Y. Q. Cai, Y. H. Liu, Y. S. Zhao, J. Feng and C. Liu, Artif. Cells, Nanomed., Biotechnol., 2017, 45, 12411246. 